\title{
STUDIES ON THE PENTOSE METABOLISM BY MICROORGANISMS
}

\section{A NEW TYPE-LACTIC ACID FERMENTATION OF PENTOSES BY LACTIC ACID BACTERIA}

\author{
SAKUZO FUKUI, AKIRA ÔI, AKIRA ÔBAYASHI, and KAKUO KITAHARA \\ Division of Zymomycology, The Institute of Applied Microbiology, \\ University of Tokyo \\ Received for publication, Oct. 30, 1957
}

The fermentation of various pentoses by lactic acid bacteria was first described by Fred, Peterson and Anderson(1), and the following formula was proposed for the reaction:

$$
\mathrm{C}_{5} \mathrm{H}_{10} \mathrm{O}_{5} \longrightarrow \mathrm{CH}_{3} \mathrm{CHOHCOOH}+\mathrm{CH}_{3} \mathrm{COOH}
$$

This formula has, heretofore, been admitted by many investigators. According to the formula equimolar quantities of lactic and acetic acids are formed from pentose, namely, the theoretical yield of lactic acid is $60 \%$ by weight of the consumed pentose. By an isotopic experiment using Lactobacillus sp. ${ }^{(2),(3),(4)}$ it has been established that the methyl and carboxyl groups of acetate arise from $\mathrm{C}-1$ and $\mathrm{C}-2$, while $-\mathrm{COOH},-\mathrm{CHOH}$ and $-\mathrm{CH}_{3}$ groups of lactate are derived from $\mathrm{C}-3, \mathrm{C}-4$ and $\mathrm{C}-5$ of pentose molecule respectively.



Fig. 1. Pathway of Pentose Fermentation by Lactobacillus pentosus.

Recently, the pathway of pentose fermentation by L. pentosus has been summerized by Horecker and his co-workers ${ }^{(5)}$ as shown in Fig. 1. In this 
scheme each pentose phosphate ester is converted to $\mathrm{D}$-xylulose-5-phosphate which is then cleaved by phosphoketolase into glyceraldehyde-3-phosphate and acetyl-phosphate. These resulting compounds are further converted to lactate and acetate respectively. By a comparative study on the fermentation of pentoses, however, we have observed the following two cases $^{(6)}: 1$ ) some strains of lactic acid organisms metabolize various pentoses according to formula (I), and 2) the others produce lactic acid in a yield of more than $60 \%$ of consumed pentoses with a small amount of formate, but no detectable amount of acetic acid. For example, Lactobacillus arabinosus readily ferments L-arabinose and produces equimolar quantities of lactic and acetic acids as expected from formula (I), while on the other hand Streptococcus faecalis produces 1.45 moles of lactate and 0.23 mole of formate per mol. of L-arabinose without any detectable amount of acetate ${ }^{(6)}$. Furthermore, the cells of $S$. faecalis grown in a medium containing L-arabinose is able to produce lactic acid in a yield of $95 \%$ of the consumed L-arabinose $(1.58$ moles of lactate per mole of L-arabinose consumed), while volatile acids are not detectable. This finding gives a clear evidence that $S$. faecalis might involve a new pathway for pentose fermentation. We have much interests in those phenomena mentioned above, especially in the new pathway of pentose fermentation.

In this paper, it will be discussed that this new type of pentose fermentation may be formulated as follows:

$$
6 \mathrm{C}_{5} \mathrm{H}_{10} \mathrm{O}_{5} \longrightarrow 10 \mathrm{CH}_{3} \mathrm{CHOHCOOH}
$$

\section{METHODS}

Strains and medium-Lactic acid bacteria used in the present experiments have been maintained as stab-culture on a nutrient bouillon-malt extract- $\mathrm{CaCO}_{3}$ agar by transferring at 3 month-interval in our laboratory. The medium for seed culture and fermentation has the following composition: peptone $1 \mathrm{~g}$; fish meet extract $1 \mathrm{~g}$; $\mathrm{NaCl} 0.5 \mathrm{~g}$; Difco's yeast extract $0.2 \mathrm{~g}$; pentose $2-3 \mathrm{~g} ; \mathrm{CaCO}_{3} 3 \mathrm{~g}$; and tap water $100 \mathrm{ml}$. Sterilization was carried out as mildly as possible under a pressure of $10 \mathrm{lbs}$. for $1 \mathrm{~min}$. in an autoclave in order to minimize the possible decomposition of pentoses into formate at a high temperature. Seed cultures were prepared by inoculating organisms from stock cultures and incubating them at $30^{\circ}$ or $45^{\circ}$ for 24 hours. The fermentations were generally carried out for 5 days at $30^{\circ}$ after inoculating $5 \mathrm{ml}$ of seed culture of each strain into $200 \mathrm{ml}$ fermentation medium, except for Lactobacillus thermophilus which is cultured at $45^{\circ} \mathrm{C}$.

Determination of Volatile Acids ${ }^{(7)}$ - The cultures were centrifuged at $4,000 \mathrm{G}$ for 10 minutes then the supernatant was acidified with sulfuric acid. Volatile acids were separated from the acidified broth by steam-distillation and identified paper-chromatographically. The quantitative determination was carried out by the fraction distillation method ${ }^{(8)}$. 
Determination of Lactic Acid-After removal of volatile acids, the acidified broth was extracted with ether for 24 hours. Acids in the ether extract were estimated as lactic acid by two methods, i.e., alkali titration and colorimetry ${ }^{(9)}$. In fact, the nonvolatile acid contained in the ether extract was identified exclusively to be lactic acid by paperchromatography.

Determination of sugars-For the determination of pentoses the Bertrand method was applied, and for the identification and determination of ketoses the cystein-carbazol reaction ${ }^{(10)}, \mathrm{FeCl}_{3}$-orcinol reaction ${ }^{(11)}$, and paperchromatography ${ }^{(12)}$ were employed.

Preparation of the cells for small-scale fermentation-The cells were prepared as follows: S. faecalis was grown in a medium containing L-arabinose and L. thermophilus $\mathrm{T}_{1}$ in $\mathrm{D}$-xylose medium. After 20 hours culture, the cells were harvested by centrifugation and washed three times with distilled water. About $2 \mathrm{~g}$ of wet cells of both organisms were obtained from each one liter of the culture broth.

Measurement of radioactivity-Radioactivities of all produts were determined after conversion to salts or barium carbonate.

\section{RESULTS}

1) Fermentation of pentoses by various strains of lactic acid bacteria

From the results of fermentation shown in Table 1, types of pentose fermentation by lactic organisms were divided into following two types: Type 1) which produced equimolar lactic acid and acetic acid from pentose according to formula (I) and Type 2) which produced more than one mole of lactate and small amount of formate but no acetate from one mole of the substrate. The latter type of fermentation may be formulated as follows:

$\mathrm{C}_{5} \mathrm{H}_{10} \mathrm{O}_{5} \longrightarrow$ more than one mole of $\mathrm{CH}_{3} \mathrm{CHOHCOOH}+x \mathrm{HCOOH}$ (III)

In these experiments it was observed that some strains were able to metabolize pentoses according to formula (I) and (III). For example, Lactobacillus thermophilus II was able to ferment L-arabinose as formula (I) and $\mathrm{D}$-xylose as formula (III). These phenomena suggest the fact that the pentose metabolizing systems of lactic organisms are sometimes altered by natures of pentose used in the culture media. Further, as shown in Table 2, L. xylosus was able to ferment D-xylose and D-ribose through different metabolic systems. On the other hand, L. thermophilus $\mathrm{T}_{1}$ metabolized various pentoses according only to formula (III) and Leuconostoc mesenteroides B07 followed exclusively to formula (I).

2) Effect of carbonate on the pentose metabolism by S. faecalis and L. thermophilus $T_{1}$

When a $\mathrm{CaCO}_{3}$-containing medium is employed, the broth may be maintained nearly saturated conditions with $\mathrm{CO}_{2}$ and $\mathrm{HCO}_{3}-$ throughout the fer- 
Table 1. Fermentation of Pentoses by Lactic Acid Organisms.

a) Fermentation of L-arabinose

\begin{tabular}{l|c|c|c|c|c|c}
\hline \multicolumn{1}{c|}{ Strain } & $\begin{array}{c}\text { Initial } \\
\text { sugar }(\mathrm{g})\end{array}$ & $\begin{array}{c}\text { Consumed } \\
\text { sugar }(\mathrm{g})\end{array}$ & $\begin{array}{c}\text { Latic } \\
\text { acid } \\
(\mathrm{g})\end{array}$ & $\begin{array}{c}\text { Acetic } \\
\text { acid } \\
(\mathrm{g})\end{array}$ & $\begin{array}{c}\text { Formic } \\
\text { acid } \\
(\mathrm{g})\end{array}$ & $\begin{array}{c}\text { Yield of } \\
\text { lactic } \\
\text { acid }(\%)\end{array}$ \\
S. faecalis & 3.75 & 3.60 & 3.11 & 0 & 0.19 & 86.4 \\
S. glycerinaceus & 3.75 & 3.75 & 3.11 & 0 & 0.24 & 82.9 \\
L. arabinosus & 3.75 & 3.75 & 1.98 & 1.56 & 0 & 52.8 \\
L. thermophilus T T $_{1}$ & 2.45 & 2.20 & 1.55 & 0 & 0.24 & 70.4 \\
L. thermophilus II & 2.80 & 1.93 & 1.18 & 0.52 & 0 & 61.2 \\
Leuc. mesent. B07 & 3.75 & 3.20 & 1.76 & 1.33 & 0 & 55.0 \\
L. brevis & 3.75 & 2.35 & 1.13 & 1.04 & 0 & 48.0 \\
Pc. hennebergi & 2.05 & 1.78 & 0.95 & 0.41 & 0 & 53.3 \\
Pc. lindneri* & 2.05 & 1.40 & 0.71 & 0.60 & 0 & 50.7 \\
\hline
\end{tabular}

* $100 \mathrm{ml}$ culture.

b) Fermentation of D-xylose

\begin{tabular}{l|c|c|c|c|c|c} 
S. lactis & 3.30 & 3.30 & 2.01 & 1.02 & 0 & 60.9 \\
L. xylosus & 4.12 & 3.06 & 1.63 & 1.10 & 0 & 53.2 \\
L. thermophilus $\mathrm{T}_{1}$ & 3.24 & 2.85 & 2.34 & 0 & 0.29 & 82.1 \\
L. thermophilus II & 2.45 & 1.45 & 0.98 & 0 & 0.41 & 67.5 \\
Leuc. mesent. B07* & 14.2 & 8.5 & 4.52 & 2.88 & 0 & 53.1 \\
L. fermentum H60 & 2.80 & 2.65 & 1.35 & 1.47 & 0 & 50.9 \\
Pc. hennebergi & 2.10 & 1.99 & 0.95 & 0.41 & 0 & 47.8 \\
Pc. lindneri & 2.10 & 1.72 & 0.84 & 0.80 & 0 & 48.9 \\
\multicolumn{1}{c}{ * $700 \mathrm{ml}$ culture. } & & & & &
\end{tabular}

c) Fermentation of D-ribose

\begin{tabular}{|c|c|c|c|c|c|c|}
\hline S. faecalis & 0.93 & 0.83 & 0.68 & 0 & 0.04 & 81.9 \\
\hline S. lactis & 0.50 & 0.50 & 0.32 & 0 & 0.07 & 64.0 \\
\hline L. xylosus & 0.80 & 0.67 & 0.50 & 0.03 & 0.07 & 74.6 \\
\hline L. arabinosus & 0.50 & 0.50 & 0.22 & 0.13 & 0 & 44.0 \\
\hline L. thermophilus $\mathrm{T}_{1}$ & 0.93 & 0.93 & 0.66 & 0 & 0.04 & 70.9 \\
\hline
\end{tabular}

$50 \mathrm{ml}$ culture.

mentation, because they are liberated from carbonate by organic acids formation from sugars. Therefore, two attempts were made in order to determine whether the carbonate fixation reaction was involved or not in this fermentation, namely 1) comparison of fermentations in the presence and absence of carbonate, and 2) investigation of the incorporation of $\mathrm{C}^{14}$-carbon into lactate by using $\mathrm{NaHC}^{14} \mathrm{O}_{3}$. 
Table 2. Pentose Fermentation Formula by Lactic Acid Organisms.

\begin{tabular}{l|c|c|c|c}
\hline Strain & L-Arabinose & D-Xylose & D-Ribose & D-Glucose \\
S. faecalis & III & non-ferment. & III & homo \\
S. glycerinaceus & III & non-ferment. & - & homo \\
S. lactis & non-ferment. & I & III' & homo \\
L. xylosus & non-ferment. & I & III' $^{\prime}$ & homo \\
L. arabinosus & I & non-ferment. & I & homo \\
L. thermophilus $\mathrm{T}_{1}$ & III & III & III & homo' \\
L. thermophilus II & I & III & non-ferment. & homo' \\
L. brevis & I & non-ferment. & & hetero \\
L. fermentum $\mathrm{H} 60$ & non-ferment. & I & - & hetero \\
Leuc. mesent. B07 & I & I & non-ferment. & hetero \\
Pc. hennebergi & I & I & - & homo \\
Pc. lintneri & I & I & - & homo \\
L. pentosus & I & I & - & - \\
\hline
\end{tabular}

* by Horecker et al.

non-ferment., non fermentable.; —-, not examined.; III', almost III.

1) In the absence of carbonate, lactic acid fermentation was proceeded by neutralizing the broth with freshly prepared $\mathrm{N}-\mathrm{NaOH}$ at a 12 -hours interval. As is shown in Table 3, S. faecalis produced 1.35 moles of lactate from one mole of $\mathrm{L}$-arabinose and $L$. thermophilus $\mathrm{T}_{1}$ produced 1.22 moles of lactate from one mole of $\mathrm{D}$-xylose, and at the same time small amounts of formate were formed by both strains. These results are similar to those of fermentations obtained by using Ca-carbonate containing medium (see Table 1), and suggests that carbonate has no effect on the pathways of pentose metabolism by $S$. faecalis and $L$. thermophilus $\mathrm{T}_{1}$.

2) In the isotopic experiments for the carbonate fixation, $\mathrm{NaHC}^{14} \mathrm{O}_{3}$ was used. One half of the $\mathrm{NaHC}^{14} \mathrm{O}_{3}$ used in this case was added at the initial

Table 3. Fermentation of Pentoses in the Absence of Carbonate.

\begin{tabular}{c|c|c}
\hline Strain & S. faecalis & L. thermophilus $\mathrm{T}_{1}$ \\
\hline Substrate & L-Arabinose & D-Xylose \\
\hline Initial sugar (g) & 1.80 & 3.05 \\
Consumed sugar (g) & 1.68 & 1.05 \\
Lactic acid (g) & 1.37 & 0.77 \\
Formic acid (g) & 0.11 & 0.18 \\
Carbon dioxide (g) & trace & trace \\
Yield of lactic acid (\%) & 81.6 & 73.3 \\
Do. mol./mol. & 1.35 & 1.22 \\
\hline
\end{tabular}

mol./mol.: moles of produced lactate per moles of consumed sugar. 
stage of fermentation process and another half at the middle-stage. As shown in Table 4, the distribution pattern of $\mathrm{C}^{14}$ among the fermentation products gave evidence that lactic acid fermentation from pentose by lactic organisms did not involve carbonate fixation reaction, but carbonate was apparently fixed into other ether-soluble non-volatile acid which was not yet identified. From these findings, we may conclude that carbonate has no effect on lactic acid production from pentoses by lactic organisms except that it merely acts as a neutralizer.

Table 4. Incorporation of Carbon Atom from Carbonate into the Fermentation Products.

\begin{tabular}{|c|c|c|}
\hline Strain & S. faecalis & L. thermophilus $\mathrm{T}_{1}$ \\
\hline Substrate & L-Arabinose & D-Xylose \\
\hline $\mathrm{NaHC}^{14} \mathrm{O}_{3}$ & 613,440 (c.p.m.) & $8,020,000$ (c.p.m.) \\
\hline Initial sugar & $1.27(\mathrm{~g})$ & $1.90(\mathrm{~g})$ \\
\hline Consumed sugar & 0.75 & 1.78 \\
\hline Lactic acid* & 1,400 & 145,600 \\
\hline Zn-lactate** & 0 & 0 \\
\hline Formic acid & 0.04 & 0.12 \\
\hline $\mathrm{CO}_{2}^{* * *}$ & 512,310 & $5,400,000$ \\
\hline Residue & 29,600 & (not measured) \\
\hline Recovered C14 & 541,910 & \\
\hline
\end{tabular}

* Ether-soluble non-volatile acid was calculated as lactic acid.

** Zn-lactate was prepared in a crystalline form.

*** $\mathrm{CO}_{2}$ was liberated from carbonate by acid-formation.

3) Lactic acid fermentation by the intact cells grown in media containing pentoses.

As was shown in Table 1, lactic acid was produced in a yield of about $87 \%$ by weight of pentose utilized, a small amount of formate being formed at the same time as a by-product by $S$. faecalis. The proportions of formate to lactate were, however, varied by the conditions of fermentation. As the systems employed in the above culture experiments seem to be unappropriate to discuss the real fate of pentose metabolism, we must employ a more simplified experimental technique to meet this purpose. Thus, we carried out lactic acid fermentation anaerobically using the intact cells which were grown in the media containing pentoses.

As shown in Tables 5 and 6 , the cells of $S$. faecalis grown in L-arabinose medium produced lactic acid in a yield of $95 \%$ by weight of the consumed $\mathrm{L}$-arabinose under anaerobic condition and the cells of L. thermophilus $\mathrm{T}_{1}$ grown in $\mathrm{D}$-xylose medium converted $93 \%$ of consumed $\mathrm{D}$-xylose to lactic acid under the same condition, but no detectable formation of formate was 
observed in each case. $\mathrm{CO}_{2}$ evolution and glycerol formation were both undetectable, however, small amounts of L-xylulose, L-ribulose and $\mathrm{D}$-xylose were formed by $S$. faecalis, and $\mathrm{D}$-xylulose by L. thermophilus $\mathrm{T}_{1} \cdot \mathrm{O}_{2}$ consumption and $\mathrm{CO}_{2}$ evolution from $\mathrm{L}$-arabinose were observed when intact cells of $S$. faecalis were used aerobically. Studies on ketose formation and pentose metabolizing system under aerobic condition will be published in the next paper.

Table 5. Fermentation of Pentoses by the Intact Cells of $S$. faecalis and $L$. thermophilus $\mathrm{T}_{1}$.

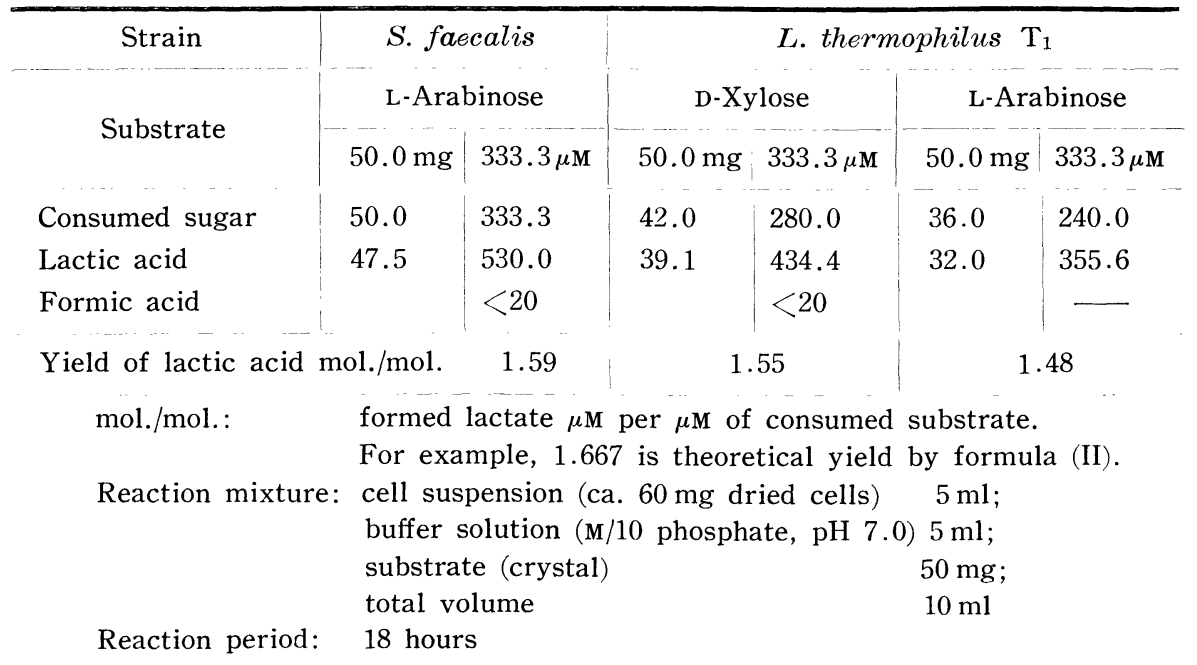

Table 6. Gas Balance in the Fermentation of L-Arabinose by the Intact Cells of S. faecalis.

\begin{tabular}{l|c|c}
\hline Gas phase & $\mathrm{N}_{2}$ & Air \\
\hline $\mathrm{CO}_{2}$ evolution $\mu \mathrm{M}$ & 0 & 5.58 \\
$\mathrm{O}_{2}$ consumption $\mu \mathrm{M}$ & 0 & 5.02 \\
Formed lactate $\mu \mathrm{M}$ & 6.66 & 2.88 \\
\hline Reaction mixture: cell suspension (ca. $15 \mathrm{mg}$ dried cells) & $0.5 \mathrm{ml}$ \\
$\quad$ buffer solution (M/15 phosphate, pH 7.0$)$ & $0.5 \mathrm{ml}$ \\
$\quad$ L-arabinose $5 \mu \mathrm{M}$ & $0.2 \mathrm{ml}$ \\
$\quad$ dist. water & $0.8 \mathrm{ml}$ \\
$\quad$ total volume & $2.0 \mathrm{ml}$ \\
Reaction period: $\quad \begin{array}{c}\text { 1 hour } \\
\text { Reaction temperature: } 35^{\circ} \mathrm{C}\end{array}$ \\
Gas balance were measured manometrically.
\end{tabular}

From these findings, we wish to propose the following fermentation formula (II) for the anaerobic pentose metabolism by $S$. faecalis and $L$. thermophilus $\mathrm{T}_{1}$. 


$$
6 \mathrm{C}_{5} \mathrm{H}_{10} \mathrm{O}_{5} \longrightarrow 10 \mathrm{CH}_{3} \mathrm{CHOHCOOH}
$$

The above formula could be accounted for only by a recycling of carbon, possibly through pentose phosphate pathway, for regeneration of $\mathrm{C}_{3}$-compound as a lactate precursor.

4) Comparative studies on fermentation of glucose, pentoses and sedoheptulose by $S$. faecalis and L. thermophilus $T_{1}$

As $S$. faecalis and $L$. thermophilus $\mathrm{T}_{1}$ are so called homo lactic acid fermenters, so the theoretical yields of lactic acid from glucose by these organisms must be amounted to $100 \%$ of consumed sugar. Actually, however, lactate is not produced theoretically because lactate formation is accompanied with cell-growth and other by-paths in fermentation. For example, as shown in Table 7, the yield of lactic acid from glucose by $S$. faecalis and L. thermophilus $\mathrm{T}_{1}$ was $87.5 \%$ and $90.0 \%$ respectively, and in both cases formate formation was observed but not acetate production. Comparison of the above data with the results obtained from pentose fermentation may suggest that there is no noticeable difference between the fermentations of pentoses and those of glucose in $S$. faecalis and L. thermophilus $\mathrm{T}_{1}$.

Table 7. Comparison of Fermentation upon Glucose, Pentoses and Sedoheotulose by $S$. faecalis and $L$. thermophilus $\mathrm{T}_{1}$

\begin{tabular}{c|c|c|c|c|c|c}
\hline Strain & \multicolumn{3}{|c|}{ S. faecalis } & \multicolumn{2}{c}{ L. thermophilus $\mathrm{T}_{1}$} \\
\hline Substrate & Glucose & L-Arabinose & Heptulose & Glucose & D-Xylose & Heptulose \\
Initial sugar (g) & 3.45 & 2.32 & 0.22 & 2.80 & 2.80 & 0.22 \\
Consumed sugar (g) & 3.45 & 2.32 & 0.22 & 2.80 & 2.80 & trace \\
Lactic acid (g) & 3.02 & 1.91 & 0.20 & 2.52 & 2.18 & \\
Formic acid (g) & 0.13 & 0.10 & 0.04 & 0.13 & 0.21 & 0 \\
Acetic acid (g) & 0 & 0 & 0 & 0 & 0 & \\
Yield of lactic acid & 87.5 & 82.3 & 90.9 & 90.0 & 77.9 & \\
(\%) & & & & & \\
Recovery of carbon & 92.1 & 87.9 & 109 & 96.0 & 87.1 & \\
(\%) & & & & &
\end{tabular}

Sedoheptulose medium was $25 \mathrm{ml}$.

Supposing the new pentose metabolizing system of lactic organisms involves the so-called pentose phosphate pathway ${ }^{(13)}$, sedoheptulose-7-phosphate and hexose-6-phosphate should be formed as intermadiates. These compounds were not detected by paperchromatography throughout our fermentation processes. It may be reasonably assumed that these compounds are so reactable that they are unable to accumulate in detectable amounts.

* The pentose metabolism by formula (II) may be designated homo lactic acid fermentation upon pentose just like that upon hexose. 
The abilities of fermenting sedoheptulose by various strains were also examined. As the results shown in Tables 7 and 8, S. faecalis and S. glycerinaceus readily fermented sedoheptulose just as glucose, giving $90 \%$ yield of lactic acid and small amount of formate from consumed sugar. On the other hand, L. thermophilus $\mathrm{T}_{1}$ could not produce any significant amount of acid in spite of its utilizing ability upon sedoheptulose (see Table 8).

Table 8. Utilization of Sedoheptulose by Lactic Acid Bacteria.

\begin{tabular}{l|c|c}
\multicolumn{1}{c|}{ Strain } & Acidity & Cell-growth \\
\hline S. faecalis & 1.00 & + \\
S. glycerinaceus & 0.10 & + \\
S. liquefaciens & 0.95 & + \\
S. faecalis B06 & 0.35 & + \\
L. arabinosus & 0 & $(+)$ \\
L. thermophilus $\mathrm{T}_{1}$ & 0.10 & + \\
L. brevis & 0 & $(+)$ \\
Leuc. mesenteroides B07 & 0 & $(+)$
\end{tabular}

Acidity: number of $\mathrm{N} / 10 \mathrm{NaOH} \mathrm{ml}$ per $2 \mathrm{ml}$ of broth containing $1 \%$ sedoheptulose after 4 days' culture.

Cell-growth: \# good growth (normal growth).

+ moderate growth.

(+) slight growth.

These results may suggest that $S$. faecalis can ferment pentoses and sedoheptulose through the pentose phosphate cycle while L. thermophilus $\mathrm{T}_{1}$ metabolizes pentose according to another pathway.

\section{DISCUSSION}

Clear evidence of the presence of a new pathway differing from the Fred-Peterson-Anderson scheme in the fermentation of pentoses by adapted cells* of $S$. faecalis and $L$. thermophilus $\mathrm{T}_{1}$ was given from the studies of substantial balance in fermentation and tracer experiment. S. faecalis was also capable of fermenting sedoheptulose with the production of lactic acid in a yield of $90 \%$ by weight of consumed substrate. Therefore, the pentose metabolizing system of $S$. faecalis may be presented as follows:

\section{Pentose $\longrightarrow$ (Pentose-5-P $\longrightarrow$ Heptulose-7-P $\longrightarrow$ Hexose-6-P)}

$\longrightarrow 10$ Lactate

or,

* Recently, we have concluded that the formation of new pentose metabolizing systems in lactic acid bacteria are adaptively induced. 


$$
6 \mathrm{C}_{5} \mathrm{H}_{10} \mathrm{O}_{5} \longrightarrow 10 \mathrm{CH}_{3} \mathrm{CHOHCOOH}
$$

In this scheme, a carbon recycling system, possibly the pentose phosphate pathway, and Emoden-Meyerhof scheme may be involved. Consequently, pentoses may probably be metabolized via hexose-6-P. In the case of $L$. thermophilus $\mathrm{T}_{1}$, although sedoheptulose was assimilated it was not fermented. So it is assumed that lactate might be produced via hexose-6-P through the other cyclic pathway of pentose, but not via sedoheptulose-7-P. Recently, E. Racker and E. Schroeder ${ }^{(14)}$ reported that ribose-5-P was converted to fructose- $6-\mathrm{P}$ through octulose- $8-\mathrm{P}$ by transaldolase. There are some possibilities for the existence of a new cyclic pathway of pentose in L. thermophilus $\mathrm{T}_{1}$. But in order to establish such a pathway, further investigation should be carried out.

\section{SUMMARY}

1) Pentose fermentation by various lactic acid bacteria can be classified into the following two types: a) Formula (I) which proceeds according to the Fred-Peterson-Anderson system, and b) formula (III) which supposedly involves a new pathway of pentose metabolism. Almost all of the examined organisms metabolized various pentoses according to either formula (I) or (III) exclusively. But, some exceptional strains fermented different pentoses by different schemes. For example, Leuconostoc mesenteroides B07 fermented various pentoses only according to formula (I) and L. thermophilus $T_{1}$ according to formula (III) exclusively. Whereas, L. thermophilus II was able to ferment L-arabinose by formula (I) and $\mathrm{D}$-xylose by formula (III).

2) From comparative study of pentose fermentation in the presence and absence of carbonate and an isotopic experiment for incorporation of carbonate into lactate, it was concluded that carbonate fixation reaction is not involved in lactate formation from pentoses.

3) Anaerobically, the cells of $S$. faecalis grown in a L-arabinose medium produced lactic acid from L-arabinose in a yield of $95 \%$ by weight of consumed sugar, and likewise those of $L$. thermophilus $\mathrm{T}_{1}$ grown in $\mathrm{D}$-xylose medium converted $93 \%$ of consumed $\mathrm{D}$-xylose to lactic acid. In both cases no formate and $\mathrm{CO}_{2}$ were formed. As a consequence of these experiments, we proposed a new formula (II) as an alternative scheme of (III).

4) From the analysis of yields of lactate from glucose, pentose and sedoheptulose, no noticeable difference in yield among these fermentations was observed. Consequently, we have concluded that so-called pentose phosphate pathway may have no inconsistency for accounting for the pentose metabolizing system of $S$. faecalis. This hypothesis, however, can not be applied for such a strain like $L$. thermophilus $\mathrm{T}_{1}$ which unable to ferment sedoheptulose. 


\section{ACKNOWLEDGEMENTS}

The authors are grateful to Dr. R. Sato for his kindness of supplying to us the preparation of sedoheptulose.

\section{REFERENCES}

(1) Fred, E. B., Peterson, W. H. and Andeson, J. A.: J. Biol. Chem., 48, 385 (1921).

(2) Lampen, J. O., Gest, H. and Sowden, J. C.: J. Bact., 61, 97 (1951).

(3) RAPPAPORT, D. A., Barker, H. A. and HaSsid, W. Z.: Arch. Biochem. Biophys., 31, 326 (1951).

(4) Bernstain, I. A.: J. Biol. Chem., 205, 309 (1953).

(5) Horecker, B. L., Health, E., Hurwitz, J., Takagi, Y. and Burma, D. P.: Reported at the International Symposium on Enzyme Chemistry 1957, No. 123.

(6) FUKuI, S., ÔI, A. and ÔBAYASHI, A.: Reported at the Annual Meeting of the Agricultural Chemical Society of Japan, April, 11, 1957.

(7) Fukui, S.: Protein, Nucleic Acid and Enzyme, 2, 49 (1957).

(8) Virtanen, A. J. and Pulkki, L.: J. Am. Chem. Soc., 5o, 3138 (1928).

(9) Barker, S. B. and Summerson, W. H.: J. Biol. Chem., 138, 538 (1948).

(10) Disch, Z. and Borenfreud, E.: J. Biol. Chem., 192, 583 (1951).

(11) Horecker, B. L., Smyrniotis, P. Z. and Klenow, H.: J. Biol. Chem., 205 661 (1953).

(12) Hochster, R. M. and Watson, R. W.: Arch. Biochem. Biophys., 48, 120 (1954).

(13) Srere, P. A., Cooper, J. R., Klybas, V. and Racker, E.: Arch. Biochem. Biophys., 59, 535 (1955).

(14) Racker, E. and Schroeder, E.: Arch. Biochem. Biophys., 66, 241 (1957). 